\title{
A Guerra Nuclear e o Direito*
}

\author{
Guido F. S. Soares \\ Mestre em Direito Comparado (Illinois, EUA); \\ Doutor em Ciência Politica (Rel. Int.) PUC-SP; \\ Livre-Docente em Direito Internacional - USP e \\ Professor Adjunto do Departamento de Direito \\ Internacional da FADUSP
}

\begin{abstract}
Resumo - Palavras Iniciais. I - Introducão. II - $O$ Direito da Guerra (Jus in Bello) e a guerra nuclear. III - O Direito de Prevençăo da Guerra (Jus ad Bellum) e a guerra nuclear. IV - Conclusões. Bibliografia de Apoio.
\end{abstract}

Sejam as palavras iniciais de agradecimento pelo honroso convite da Associação dos Docentes da USP, a já festejada ADUSP, no sen tido de integrar o painel de ilustres conferencistas deste Curso de Divulgação Causas e Conseqüências de uma Guerra Nuclear, que traz uma contribuição das mais valiosas; de acrescentar à nossa USP, ainda uma demonstração de sua importância como instituição de «alma mater» da cultura, no ano de seu Cinqüentenário.

Igualmente, não pode deixar de ser enfatizada a relevância dos estudos sobre a guerra nuclear, questão que tem a universidade brasileira, pelo menos até a realização do presente curso, tratado com desdém. Se as causas da omissão podem ser imediatamente detectadas, sendo a Universidade um centro de elaboração e irradiação da cultura, aparentemente o fenômeno guerra, por sua natureza, estaria excluído do rol de suas preocupações. Contudo, a patologra individual e societária estão presentes nos cursos de Medicina, de Crimino. logia, nos vários capítulos de Direito Constitucional Brasileiro (ảiga-se: Direito Eleitoral vigente), para confirmar que o combate ao mal só se pode fazer, após o conhecimento da normalidade, as causas de sua deterioração e da utilização dos instrumentos para a prevenção do mesmo, ou remédio de suas seqüelas. Por tal abertura aos dias que correm, onde a guerra nuclear é o espectro que ronda a existência do homem contemporâneo, merecem elogios a ADUSP e entidades patrocinadoras deste Curso, uma vez que revelam a face da Universidade de São Paulo de, ao lado de propor-se ao «desenvolvimento e

(*) Aula proferida no Curso de Divulgação, CAUSAS E CONSEQtênCIAS DE UMA GUERRA NUCLEAR, patrocinado pela Associação dos Docentes de USP, ADUSP, pela Associação Nacional dos Docentes do Ensino Superior, ANDES, pela Sociedade Brasileira pelo Progresso da Ciência, SBPC, pela Sociedade Brasileira de Física, SBF e pela Academia Brasileira de Ciências, ABC, no Auditório «Abrão de Morais», do Instituto de Física, na Cidade Universitária, São Paulo, SP, no dia 28 de março de 1984. 
a promoção da cultura, por meio do ensino e pesquisa», ao tentar conscientizar a todos sobre a questão vital de nossos tempos (as cau. sas e conseqüências de uma guerra nuclear), realizar a meta da «pres. tação de serviços à comunidade» (Estatuto da USP, art. 2", I e III), causa eficiente e final da Universidade de São Paulo. E, assim, devo, com a dupla satisfação de membro associado da ADUSP e de Professor de Direito do Largo de São Francisco, vir trazer minha contri. buição aos estudos sobre a paz (que devem estudar a guerra), numa afirmação dos princípios que regem uma das disciplinas que leciono, «Organizações Internacionais», e que se acham solenemente consagra dos no Estatuto da UNESCO: as guerras se iniciam na mente dos homens e, portanto, é nela que se deve extirpar sua origem. Assim sendo, na qualidade de antigo acadêmico do Largo de São Francisco e, atualmente, Professor de Direito da USP, cumpro com o duplo dever: de fidelidade aos ideais de meus antigos mestres e de fidelidade às obrigações de Professor da USP.

\section{I - INTRODUÇÃO}

Conforme se caminha da Antigüidade Clássica para os dias correntes, pode-se observar que, à medida em que as guerras ganhani universalidade no relativo a seus participantes, tornam-se elas mais e mais pontos demarcadores de fases históricas definidas. Se gregos e romanos consideravam a guerra como o estado normal das civilizações, entrecortado por espaços temporais de periodos de paz, o homem moderno, sobretudo a partir da formação do Estado moderno, considera a guerra como um fenômeno da teratologia cultural, que entrecorta os períodos normais de paz, tidos esses como o estado sadio da civilização. Assim sendo, na visão moderna, os periodos de paž são o estado de higidez da civilização e as guerras um fator de tur. bação; de simples ocorrência previsível, passam as guerras a constituir um ponto demarcatório de um ciclo que se termina, e de sua passagem para outro ciclo, que começa marcado pelos resultados das vitórias c das derrotas. $\mathrm{Na}$ verdade, os grandes tratados de paz refletem um rearranjo do mundo e o sepultamento de um ciclo histórico, que se exauriu no confronto bélico de forças políticas que predominavanı anteriormente. São evidentes os caracteres dermarcatórios dos tratados de paz, nos Congressos de Vestfália de 1648 (fim do mundo medieval e consagração do nascimento do Estado absolutista), de Viena de 1840 (fim dos ideais imperialistas de Napoleão e a consagração do sistema do Concerto Europeu) dos Tratados de Versalhes de 1919 (fim da predominância européia na politica internacional e estabelecimento de um sistema de segurança coletiva, de responsabilidade mundial, com a fundação da Sociedade das Nações) e, finalmente, nos dias atuais, os tratados de Yalta, Potsdam, Moscou, ... de São Francisco, que terminaram com o sistema da SdN e instituíram o sistema de segurança coletiva na figura das organizações internacionais de vocação universal, em especial a ONU. Isto posto, tenha-se em mente, na análise da situação das relações internacionais atuais, que vive- 
mos numa época marcada pelo final da Segunda Guerra Mundial $(1939 / 45)$, cujos traços característicos marcam as relações de força existentes naquele conflito, até o momento em que nova confrontação bélica venha a mudar o "status quo», se admitirmos que a história seja recorrente no seu evolver.

Outro dado preliminar a considerar é a aparente contradição de um estudioso do Direito interessar-se pelo fenômeno da guerra, ela mesma a negação da cultura; com efeito, na sua vocação de tenta: a ser a realização da justiça nas relações humanas, de ser, no dizer de um jurista romano, a «arte do bom e do justo» (Celsius, «ars bonı et $æ$ qui») a impressão que talvez ficaria a uma pessoa mal informada, seria de que o estudo do fenômeno-guerra não teria lugar no Direito. Contudo, não se deve perder de vista que o Direito regula atividades do homem naqueles aspectos que envolvem escolha de valores, quer dizer, das atividades livres do homem, e que envolvem opções, seja entre os valores justos e desejáveis para a sobrevivência da comunidade (e portanto os valores vigentes) seja entre outros valores não vigentes, cuja eleição implica na negação daqueles. Falso ou verdadeiro é uma relidade inexistente no Direito, da mesma forma em que inexiste nas Ciências da Natureza, em especial, o problema da violação de uma lei dai Física, da Química ou da Biologia. Se existe possibilidade de violação das leis jurídicas, porque nos encontramos no mundo da conduta livre do homem, é necessário um sistema de sanções para o violador, de cujas finalidades, se destaca aquela de dissuadir a eleição de valores que impliquem violação da norma. O Direito é compatível com a utilização de medidas coercitivas contra o violador da norma, uma vez que pretende estarem vigentes aquelas de resguardo dos valores fundamentais da comunidade e não outras, na expressão do jurista oitocentista italiano Rosmini: «o direito brilha quando violado».

Não é estranho ao jurista e ao legislador o fenômeno da viola. bilidade nas normas jurídicas; ao contrário, ao estabelecer a descrição do justo, lateralmente, estabelece um sistema de prêmios e castigos, pois sabe que a norma jurídica pode ser violada. Assim, ao jurista e ao legislador cabe a dupla tarefa de descrever e criar o estado de higidez da comunidade, ao mesmo tempo em que estuda e descreve seus estados de morbidez, fazendo-os acompanhados dos remédios dé evitar, reparar ou estancar um atentado à sanidade do corpo social. As normas jurídicas, pois, nada mais são do que a descrição e imposição das condutas tidas por desejáveis, e ao mesmo tempo, da criação de sistemas coercitivos para seus violadores.

A guerra é um fenômeno recorrente na história e representa, como se disse, um estado de morbidez, de violação de valores de sobrevivência do homem. Sendo assim, desde toda Antigüidade, procurou o homem evitar, reparar e estancar os efeitos dos males por ela causados. Entre os povos antigos, os confrontos bélicos se inicia. vam e terminavam, observados ritos religiosos, que prenunciam as regras do Direito Internacional contemporâneo e, se assim faziam, era 
pela necessidade de delimitar: tempos de paz e tempos de guerra, situações entre participantes e não-participantes, entre aliados e neutros, entre beligerantes e população civil.

A primeira obra que se escreveu de Direito Internacional Público, segundo alguns, foi o clássico «De Jure Belli ac Pacis»» (Do Direito daa Guerra e da Paz), de autoria do holandês Hugo Grotius (1583-1645), cujo título bem demonstra as concepções dos tratadistas da época, e que se prolongariam até após a Primeira Guerra Mundial (1914/18): há duas situações fortemente distintas, cada qual com regras próprias e sem intercâmbio mútuo: a situação de paz, regida pelo «jus pacis», e delimitada por situações de guerra, período em que teria seu começo clara e insofismavelmente fixado num ato solene (a declaração de guerra formal ou o começo das hostilidades), teria um término regido por normas rígidas e determinadas pelo consenso dos povos denominados «civilizados» (assinatura do fim das hostilidades e compensações recíprocas através de um tratado solene de paz), com todo o repertório de soluções a situações bélicas, tais a conduta das hostilidades, o respeito aos prisioneiros inimigos e aos bens dos cidadãos não-beligerantes, a neutralidade, e as relações com entidades políticas excluídas dos campos de batalha. Claro está que a concepção clássica de guerra para o Direito Internacional pressupunha dois fatores for. mais no tempo: um ato de começo e um ato de fim; entre um e outro, a guerra, e entre dois atos de fim, a paz.

Estudos modernos, contudo, levaram à conclusão de que o Direito Internacional tem ainda outra função que a de simplesmente regular as relações interestatais em tempo de paz e em tempo de guerra. Fundamental é a obra do Prof. Louis Delbez, que veio trazer novas perspectivas para o assunto polêmico do chamado «Direito da Guerra», reveladas no próprio título do trabalho «Les Principes Généraux du Droit International Public, Droit de la Paix, Droit Préventif de la Guerre, Droit de la Guerre» (Paris, $3^{\text {a }}$ ed., Lib. Gén. de Droit et de Jurispr., 1964). Haveria, na perspectiva do Prof. Delbez, um DIREITO DA PAZ (Jus pacis), que regula as relações entre Estados, entre estes e organismos internacionais, no tempo de paz, tais as relações pacíficas de comércio e navegação, o reconhecimento de Estados e Governos, a delimitação de territórios e fronteiras terrestres, marítimas e aéreas, a situação de bens comuns e internacionais, o envio de missões diplomáticas e consulares e sua situação jurídica nos Estados receptores, o nascimento, atribuições e término dos organismos internacionais, os atos internacionais, em suma, toda a gama de ações entre os atores internacionais, em estado de paz total. Outro direito haveria, o DIREITO PREVENTIVO DA GUERRA (Jus ad bellum), que pressupõe ainda um estado de paz na comunidade internacional, mas onde já há ameaças à sua turbação e, sendo assim, as relações entre os atores internacionais já estariam deterioradas e exigiriam remédios preventivos do mal maior, que é a guerra: as soluções pac1ficas de litígios internacionais, tais a mediação, os bons ofícios, a conciliação internacional, a arbitragem por um terceiro não parte no 
litígio, bem como a solução judiciária de litígios ajuizados perante tribunais judiciários internacionais, além das considerações sobre a retorsão, as represálias econômicas, destacando-se, nesse capitulo, o estudo do atual sistema de segurança coletiva, representado pela atuação dos organismos internacionais, tais como a ONU e os organismos político-militares de segurança regional: a OEA, a OTAN (ou NATO, em inglês) o Pacto de Varsóvia... Enfim, o DIREITO DA GUERRA (Jus in bello), do Prof. Delbez, não foge à tipicidade de Grotius, com as inovações que a inovação na arte de destruir o próximo trouxe para a história: os princípios do direito da guerra, os efeitos gerais do estado de guerra, a guerra terrestre, a maritima e a aérea, a neutralidade, e o fim da guerra. A contribuição do Prof. Delbez é inestimável para a questão, uma vez que tornou patente o papel dos instrumentos preventivos da guerra, reservando-lhes mesmo um lugar de destaque em sua doutrina, onde avulta a importância dos organismos internacionais universais, do qual o mais significativo é a ONU, em especial nos seus esforços pelo desarmamento; diga-se, mesmo, que a vital questão do desarmamento convencional ou nucleal, que nas doutrinas outras não têm um apropriado tratamento ou loca lização, em Delbez, coloca-se dentro de uma das preocupaçōes do JUS AD BELLUM, uma vez que são a forma por excelência mais perfeita da prevenção da guerra, e pois, do resguardo da paz, finalidade pr. meira e suprema do Direito Internacional.

\section{II - O Direito da Guerra (Jus in Bello) e a guerra nuclear}

Na presente exposição, importa considerar, em primeiro lugar, os princípios do DIREITO DA GUERRA, a fim de desvendar neles, a partir das regras fixadas e aceitas pela comunidade dos Estados, qualquer aplicabilidade à guerra nuclear. Uma observação preliminaı se impõe no trato dessa questão e que revela a importância do papei de previsão de ações lesivas ao homem, que deve estar contida na norma jurídica, sobretudo de Direito Internacional de fundo punitivo ou repressivo. A exemplo, o direito, em geral, pune ações que define como delituosas, conforme a tipologia fixada por lei e que é fornecida pela história da delinqüência ou pela imaginação do legislador, tais os crimes mais corriqueiros, o furto, o roubo, a sedução, etc. tão antigos quanto o homem, ou crimes novissimos que só o homem do Século XX pode cometer hoje (os crimes contra a ecologia), ou ainda outros, igualmente novíssimos, que ainda não foram cometidos, mas que estão previstos pelo legislador (o crime, que denominaremos «nuclear» do art. 20 da Lei $n^{\circ} 6.453$, de $17 / \mathrm{X} / 1977$, «dispöe sobre a responsabilidade civil por danos nucleares e a responsabilidade criminal por atos relacionados com atividades nucleares e dá outras provídências», verbis: Produzir, processar, fornecer ou usar material nuclear sem a necessária autorização ou para fim diverso do permitido em lei. Pena: reclusão, de quatro a dez anos»). No particular da capacidade de previsão de atos futuros, o Direito Internacional é extremamente generoso: não se pode admitir como possível a instalação de engenhos militares na Lua, Marte, ou em uma vaga estrela da Ursà 
Maior, por uma questão de engenharia naval espacial;.. mas, nem por isso, o Direito Internacional deixou de legislar sobre a possibilidade mais do que aleatória no futuro, através do Tratado sobre Princípios Reguladores das Atividades dos Estados na Exploração e Uso do Espaço Cósmico, inclusive a Lua e Demais Corpos Celestes, adotado pelá Assembléia Geral da ONU em 19 de XII de 1986, promulgado sobremaneira, seu art. IV, $\S 2$, verbis: «Todos os Estados-partes do Tra. tado utilizarão a Lua e os demais corpos celestes, exclusivamente para fins pacíficos. Estarão proibidos nos corpos celestes o estabelecimento de base, instalações e fortificações militares, os ensaios de armas e qualquer tipo e a execução de manobras militares...).

Não podendo fugir ao formalismo que lhe é típico, em particulai quando define condutas proibidas ou situações anômalas, o Direito Internacional define a guerra através de seus postulados lógico-for mais, sem dúvida bastante distintos daqueles de que se serviriam um sociólogo preocupado com o estudo das relações de conflitos societá rios, ou um estrategista militar, ou ainda um militante de movimento pacifista. Para o jurista, a guerra é, no dizer de Charles Rousseau, Professor da Faculdade de Direito da Universidade de Paris, «uma luta armada entre Estados, com a finalidade de fazer prevalecer um ponto de vista político, e de acordo com os meios regulamentados pelo direito internacional» (in Droit International Public, Paris, 6 ${ }^{\text {a }}$ ed., Dalloz, p. 336, 1971).

Não é a guerra uma «guerra» civil ou uma ação armada contra piratas, corsários ou insurgentes. Nem é uma rixa generalizada, im. plicando esta figura de Direito Penal a existência de um conflito entre bandos, eventualmente armados (art. 137 do Código Penal brasileiro, dentre os crimes contra a pessoa). Trata-se de uma relação hostil entre Estadoss, na qual se defrontam inimigos públicos («hostes») e não privados («inimici»). Suas finalidades são de impor um valor político nacional, que representa um valor fundamental para os Estados em confronto, e, por tais razões, todas as forças produtivas nacionais são empregadas no esforço bélico. Enfim, seu início, sua condução e seu término devem estar regulados pelo Direito Internacional. Sua fundamentação jurídica passou pelos motivos da «guerra justa» do direito medieval, pela «guerra duelo» (reafirmação do princípio da «raggione di Stato» de Maquiavel, na fórmula de que 0 Estado é o único juiz das razões de uma guerra), para a teoria da guerra-delito (proibição de qualquer guerra, sendo a intervenção coletiva sob a égide dos organismos internacionais considerada como «operação de polícia»), segundo relato do citado Prof. Delbez, op. cit. pp. $389 / 400$.

As fontes do Jus in bello são, ora costumes internacionais vigentes entre Estados, ora normas escritas elaboradas por estes, ora, enfim, os princípios gerais de direito (em especial na guerra aérea, onde, na Segunda Guerra Mundial, se verificara imensa lacuna do Direito Internacional, pelo fato de ter sido a primeira vez na história em que se empregara a aviação como arma de guerra ofensivo-defensiva). 
São inúmeros os textos normativos constantes de tratados internacio nais vigentes na atualidade, e cuja análise não se comportaria no âm. bito do presente trabalho, pois seu título é «A Guerra Nuclear e o Direito»; conforme será visto mais além, a guerra nuclear foge à tip: cidade das guerras convencionais, para as quais as regras do Direito da Guerra foram elaboradas. Contudo, vale a pena enumerar aqueles textos, pelo menos os mais significativos, para, no que se vai dizer a seguir, se mostrar a precariedade da paz atual e a impossibilidade de o Direito Internacional prever remédios para situações de conflito nuclear, ou de prever os curativos para eventuais ferimentos na comunidade dos Estados neste final do Século XX: a declaração de Paris, de 16 de abril de 1856, sobre os princípios de direito marítimo em tempo de guerra, a convenção de Genebra de 22 de agosto de 1864, denominada de Cruz Vermelha, relativa aos militares feridos nos campos de batalha, as várias convenções assinadas em Haia, em outubro de 1907 (Conferências da Paz) relativas a rompimento de hosti. lidades, dos direitos e deveres das potências e pessoas neutras, a navios mercantes, à colocação de minas submarinas automáticas de contato, relativas à guerra maritima; no periodo do Entre Guerras, e após a amarga experiência da Primeira Guerra Mundial, o protocolo relativo à proibição do emprego na guerra, de gases asfixiantes, tóxicos ou similares e de meios bacteriológicos (Genebra, 17 de junho de 1925), a convenção relativa à melhoria da sorte dos feridos ou enfermos nos exércitos em campanha (revista em Genebra a 27 de julho de 1929) a relativa ao tratamento de prisioneiros de guerra (Genebra, 1929) o tratado naval de Londres de 22 de abril de 1930, referente à ação bélica de submarinos em relação a navios mercantes; e apos a Segunda Guerra Mundial, as várias convenções concluídas em Genebra em 1949 (12 de agosto) e 1957 (10 de maio), assim como as Convenções de Haia de 14 de maio de 1954, para a proteção de bens culturais em caso de conflito armado.

Note-se que várias convenções foram assinadas e reafirmadas em épocas distintas. Assim fizeram as Nações, não só para reiterar seus princípios, que tinham sido violados em conflitos imediatamente ante riores à segunda data da assinatura, mas também para modernizar seus princípios, em face das inovaçōes tecnológicas na arte bélica (como é o caso da extrema modificação na guerra marítima com a introdução de submarinos, ou ainda, a sensível superioridade no poder mortífero das armas dos exércitos em terra).

As finalidades do «Jus in Bello» não são de evitar a guerra, mas tão-somente de abreviar sua duração e de prevenir meios cruéis e desnecessários contra o inimigo e, sobretudo, salvaguardar os nãocombatentes (população, cidades e indústrias civis) dos efeitos da destruição. E mister ter em mira que o Direito da Guerra visa, sobremaneira, a estabelecer uma regulamentação de atividades destruidoras do inimigo, que se pretende vencido, mas nunca através de um resultado de terra arrasada; a atividade guerreira visa à vitória, mas com vencedores na situação de dominação aos vencidos, prefe- 
rencialmente pessoas vivas, capazes de reconstruir seu parque indus. trial e pagar as indenizações ao vitorioso. Uma vitória sobre cadave. res, à maneira de Átila, Tamerlão, ou ao gosto de qualquer outro general neurótico, não é próprio das características dos confrontos bélicos entre as unidades politicas - os Estados - na atualidade.

Todas as regras do Direito da Guerra têm pressupostos lógicos e factuais evidentes, que necessitam ser realçados, a fim de deixar claras aquelas finalidades. Mesmo após terem vivenciado a experiência de duas guerras mundiais (14/18 e 39/45), os Estados năo foram capazes de transpor os postulados do Direito da Guerra, formulados a partir do começo do Século, para as exigências que já se verificavam no primeiro conflito de âmbito mundial. O fato é que as leis da guerra foram elaboradas tendo em vista conflitos bélicos denominados de guerras convencionais, ou guerras limitadas, cujos pressupostos eram: a) um teatro de operações firmemente delimitado no espaço e, como tal, respeitado pelos beligerantes e neutros (espaço onde se desenrolam as operações bélicas de confronto de forças militares definidas e ligadas a um Estado muito bem caracterizado, ou em outras palavras, confronto de pessoal a serviço de Marte, com uma investidura e um uniforme assim exteriorizados); b) um teatro de guerra igualmente delimitado, onde os objetivos militares deveriam estar identificados, tais as fábricas de materiais e equipamentos militares, as pontes, estradas e outras linhas de comunicações entre a frente de combate e a retaguarda; c) em consequiência, as operações militares deveriam restringir-se a destruir tais objetivos, sempre con a finalidade de minar as forças do adversário, respeitado o pessoal nãobeligerante e, sobretudo, a população civil, os santuários considerados lugares neutros (hospitais, campos de reunião de prisioneiros de guerra ou refugiados), as pessoas e bens não-participantes da contenda, tais os navios mercantes e os bens comuns à humanidade (obras de arte).

Ora, o que já se verificaria no correr da Primeira Guerra Mundial, seria a emergência de um tipo insuspeitado de guerra; na verdade, a Grande Guerra configuraria o que se convencionou denominar uma guerra total, que, por sua vez, engendraria uma estratégia global (ou na concepção do General Beaufre, grande teórico da moderna guerra, uma estratégia indireta, diferente daquela clássica, apelada de direta) e que, nos resultados do final do conflito, clamariam por uma paz em termos igualmente globais.

A guerra é total, em primeiro lugar, pela extensão geográfica do teatro de operações e do teatro de guerra para além dos campos de batalha determinados entre as partes em conflito, segundo as tradicionais regras costumeiras ou convencionadas. As interligações das Nações pelos interesses econômicos em um mundo apequenado pelo comércio internacional e pela expansão do colonialismo dos Países europeus em séculos anteriores, fizeram com que uma deflagração no continentee europeu estendesse as áreas de confrontação bélica aos outros continentes. Na Grande Guerra, pela primeira vez, partici. 
pam Estados do Novo Continente, em especial os EUA, que por não sentirem os efeitos da destruição física no próprio território e, pela descomunal capacidade produtiva, entravam como atores na cena européia, agora já universal, em substituição à força do tzar, tradicional no equilíbrio europeu, que se refluíra para dentro do próprio país, para consolidar a Revolução de Outubro.

Em segundo lugar, guerra total, ainda geográfica, mas de uma geografia estratégico-militar: a enorme dependência dos exércitos e armadas nacionais das linhas de suprimento, assim como a importância da retaguarda civil (veja-se o papel da rápida transformação das indústrias civis em indústrias militares já na I GM.), fizeram ainda a extensão dos alvos militares para além das linhas de combate, na forma de destruição de alvos como fábricas de qualquer tipo, militare; ou não, as próprias cidades (vejam-se os bombardeios sistemáticos d $\epsilon$ cidades como Londres e Dresdem, naturalmente transformadas em cidadelas e, conseqüentemente, alvos de destruição, sobretudo na II GM.) e alvos de ações terroristas e de sabotagem, com objetivos militares (o que explica a extremada prática da espionagem e da infiltração disfarçada, os «Quintas Colunas», nos dois últimos conflitos mundiais).

Em terceiro lugar, as guerras atuais se dizem totais, jã não num sentido geográfico, mas devido a profundas modificações de seus obje tivos, que passam de militares, a se constituírem em objetivos globais, exigentes de uma mobilização de espírito e das forças produtivas da Nação, a um nível sem precedentes na História. São agentes nacionais a serviço da guerra, não só o soldado, mas toda a população, desfazendo a separação clássica entre beligerantes e não-beligerantes: todas as forças nacionais se encontram mobilizadas e à população civil se aplica a disciplina rígida exigida dos militares em tempo de guerra, causando, assim, o comprometimento dos partidos políticos com as eventuais reivindicações dos trabalhadores, que deixariam de lado as conquistas conseguidas desde as lutas da revolução industrial, em favor de promessas dos políticos para os futuros dias de depois da vitória (e por tais razões se pode compreender a emergência da Organização Internacional do Trabalho, por pressões dos trabalhadores, exatamente como a parte XX do Tratado de Versalhes de 1919). A «nação em armas», slogan de que se serviram os políticos para sustentar suas posições e que pode bem explicar o caráter globalizante das duas guerras mundiais, explica, igualmente, o aparecimento de corpos de voluntários, na qualidade de beligerantes, que, na figura dos «partisans» na II Guerra Mundial, vieram a colocar novos problemas do tratamento dos prisioneiros de guerra (se inimigos, no sentido formal, aos quais se deve respeito, nos termos das regras preestabelecidas, ou se terroristas, ou ainda, se criminosos comuns). Por outro lado, o recrudescimento das táticas de guerrilha e da guerra revolucionária, vieram, de outro lado, a fazer esmaecer a distinção formal entre beligerante e não-beligerante, entre população civil e tropas regulares, causando completo caos no que respeita à 
aplicação do Direito da Guerra, que se baseia na distinção incontornável entre o indivíduo regularmente convocado e a serviço das forças armadas de um Estado, exteriorizado pelo uso de um uniforme militar, e sem sombra de dúvida, sob um comando amigo ou inimigo. O guerrilheiro, «partisan» ou mesmo um simples cidadão que auxilia no esforço bélico, passa a ser assimilado ao soldado regular, com as conseqüências de que as represálias praticadas no campo de batalha se introduzem nas cidades ocupadas.

Em quarto lugar, o índice de potencialização que a tecnologia representa para os meios de transportes e de telecomunicações, assim como para os meios de defesa e ataque, vieram a modificar em pro fundidade as regras do Direito da Guerra. As hidrelétricas, ferrovias, rodovias passam a ser alvos militares de destruição, pouco importando que a energia gerada, ou os meios de transportes servissem a objeti. vos bélicos ou civis. Por outro lado, o desenvolvimento na tecnologia bélica trouxe uma reversão numa regra bastante antiga, de que as guerras se vencem com homens (tanto no sentido de contingente, quanto no sentido de coragem e bravura). Mesmo com a invenção e aperfeiçoamento do canhão, da bazuca ou mesmo da granada de uso individual, a relação entre poder de uso (número de homens para operar o engenho) e poder de destruição (número de soldados postos fora de combate) continuaria a ser o mesmo que nas guerras antigas: a exemplo, 5 homens para disparar um canhão, em relação a 5 outros postos fora de combate. Contudo, a revolução em tais termos se daria com a utilização da metralhadora, com seu poder indiscriminado de fogo circular, operada por dois homens, ou ainda, mais ciaramente na II Guerra Mundial, a utilização da aviação de ataque (bombardeiros), ou ainda, a inacreditável façanha de 5 homens, que se encon travam a bordo do «Enola Gray», o avião que lançou a bomba «Little Boy» sobre Nagasaky, terem destruído milhares de vidas, colocando em cheque toda a força bélica do Japão.

$\mathrm{Na}$ verdade, o poder destrutivo dos engenhos nucleares, aliado à fantástica revolução dos meios de transporte das armas nucleares (os mísseis balísticos intercontinentais, ICBMs, colocados em silos móveis ou em submarinos nucleares) tornaram os postulados lógicos do Direito da Guerra totalmente inadequados às realidades presentes ou futuras. O fator território, base em que se assentava o postulado das guerras convencionais, e que já tinha sido minado com as vivências de duas guerras totais, na hipótese de uma guerra nuclear, ainda que delimitada a dois beligerantes, desaparece como elemento fundamentai.

Com efeito, os efeitos de uma explosão de arma nuclear, por mais limpa que seja uma bomba, ultrapassam o território do inimigo, indo produzir efeitos danosos a Estados neutros ou mesmo a Estados aliados. Pelas mesmas razões, se torna impossível distinguir entre população civil e objetivos militares, pois a destruição de um alvo bélico determinado, uma fábrica, ou ponte, ou tropas regulares, causará um desprendimento de radioatividade, que levada pelas águas ou pelo ar, certamente ultrapassarão os objetivos militares visados. Te- 
nha-se em mente que as correntes atmosféricas de ar e de água não conhecem fronteiras políticas ou jurídicas e são, de qualquer modo, insensiveis a um civil ou militar, a um amigo ou inimigo, a nacionaís de outros países e aos próprios nacionais do Estado responsável peio artefato nuclear.

Desaparecido o postulado indeclinável da existência e delimitação de um teatro de guerra e de um teatro de operações, na guerra nuclear ficam por terra os conceitos do Direito da Guerra, e com mais forte razão, os seus objetivos de abreviar a duração do con. flito e de tornar proibidas as destruições desnecessárias e cruéis. A guerra nuclear é assim uma técnica de destruição que se baseia no princípio da terra arrasada, da rendição incondicional e do predomínio dos vencedores sobre escombros e cadáveres. Mesmo as tentativas de «limpar» as bombas, evitando a radioatividade residual, não conseguem apagar os efeitos das armas nucleares para além dos objetivos militares.

$\mathrm{Na}$ lógica da guerra nuclear, o princípio de que o ataque de surpresa leva vantagem sobre a preparação dos meios de defesa (a dialética entre a espada e o escudo), sofre uma variação. O primeiro ataque («first strike») pode representar alguma vantagem, do ponto de vista estratégico-militar, mas quem tiver uma capacidade de resposta ( «response») superior ao primeiro ataque (que já enfraqueceu o atacante, pois os mísseis já partiram), aliada a uma capacidade de anular ou de enfraquecer os efeitos do mesmo, terá superiores vantagens nos efeitos de destruição. Por tais razões, pelo menos na estratégia norte-americana, assistiu-se a uma passagem da estratégia da «retaliação maciça» (massive retaliation) para uma de «resposta flexível» (flexible response), significativa não só da perda do monopólio nuclear em favor da URSS, mas também da mudança de polltica da «massive retaliation» de Foster Dulles para uma de negociação diplomátira de MacNamara.

O fato é que inexiste possibilidade na guerra nuclear de querer aplicar-se qualquer regra do Direito da Guerra, elaborado, como se disse, a partir da experiência histórica das guerras convencionais $\epsilon$, com algum esforço exegético, aplicável também às guerras totais. Mas, se os postulados da guerra nuclear chegam a negar aqueles do «Jus in Bello», por se tratar de uma situação novissima, onde nern sequer existe o território inimigo, onde a estratégia é de aniquilação total do mesmo, todas as precauções e regras jurídicas anteriores desaparecem.

No que concerne à vocação do Direito da Guerra de abreviar o conflito, a própria tecnologia bélica da atualidade já se encarregou de fazê-lo: os efeitos de uma guerra nuclear são instantâneos, de destruição total das forças convencionais, e, iniciada a guerra nuclear, nenhum Estado voltará passos atrás e passará a adotar uma estratégia convencional, mas sim, continuará com a guerra nuclear, com seus efeitos de extermínio total do adversário. Tal é o efeito do que 
se convencionou denominar a «escalada nuclear». Por outro lado, a extrema rapidez dos meios de acionamento dos dispositivos da guerra nuclear, anulará qualquer veleidade de negociação durante o conflito, e, nem sequer regras de evitar atitudes cruéis e desnecessárıas serão possíveis. A guerra nuclear, ela mesma, já é o meio mais cruel e desnecessário existente, jamais inventado pelo homem, uma vez que sua finalidade é a destruição total do inimigo, sem contemplação, sem negociação de resultado, sem possibilidade de um mínimo de racionalidade (e portanto, de humanidade).

Isto posto, ou seja, minadas as bases factuais em que se assenta - Direito da Guerra, todas as suas regras desaparecem, e aquilo que as guerras totais começaram a matar (o respeito aos não-beligerantes, aos feridos, aos inimigos aprisionados, aos Estados neutros, aos bens culturais), a guerra nuclear se encarregará de, em definitivo, sepultar de vez, colocando uma lápide melancólica na tentativa de o homem, conscientemente não podendo evitar a guerra, pelo menos procurar minorar seus efeitos maléficos.

\section{II - O Direito de Prevenção da Guerra (Jus ad Bellum) e a Guerra Nuclear}

Já que o JUS IN BELLO não pode existir numa guerra nuclear, seja ela deflagrada ou mesmo numa hipótese de possível início, o que se verifica é que os estudos do JUS AD BELLUM, (relembre-se: o Direito Preventivo da Guerra, na terminologia do Prof. Delbez), ganham relevância. Se é impossivel antever a aplicação do Direito da Guerra ao conflito nuclear, as tentativas no campo do direito para preveni-la são de transcendental importância, a ponto de suplantar as tentativas jurídicas de buscas de minoração dos efeitos da mesma. $\mathrm{Na}$ verdade, os esforços de estabelecer padrões de conduta para os Estados, a ponto de se chegar a um banimento da possibilidade de um confronto nuclear bélico, constituem a preocupação central dos estudiosos do Direito Internacional da atualidade.

A transposição das regras do desarmamento convencional, a forma por excelência da prevenção da guerra, para as questões relacionadas com a guerra nuclear, contudo, logo se revelou impossivel, o que determinaria a elaboração de normas próprias relacionadas com o fenômeno novíssimo da utilização da energia nuclear para fins bélicos. $O$ desarmamento nuclear, na verdade, acabaria por eclipsar o problema do desarmamento em geral, mostrando a verdadeira face, revolucionária, da utilização da energia nuclear.

Nascida em 26 de junho de 1945, com a assinatura em São Francisco de sua Carta, a Organização das Nações Unidas previa no art. 26 de seu estatuto constitutivo, competência do Conselho de Segurança para encarregar-se de formular «os planos a serem submetidos aos Membros das Nações Unidas para o estabelecimento de unı sistema de regulamentação dos armamentos». Contudo, com a para. 
lisação da atividade do Conselho de Segurança, em virtude das oposi. ções políticas entre EUA e a URSS no auge da Guerra Fria, tal competência foi deslocada para a Assembléia Geral, que passcu a ganhar relevo nos assuntos de desarmamento. Assim sendo, foi criada uma «Comissão dos armamentos do tipo clássico», tentativa então já ultrapassada pelos acontecimentos, uma vez que Hiroshima e Nagasaky tinham acontecido logo após o nascimento da ONU (explosões em agosto do mesmo ano de 1954). Verificada a defasagem da ONU em relação à indeclinável especificidade dos armamentos nucleares, foi criada uma Comissão de Energia Atômica, órgão subsidiário da Assembléia Geral, composto dos mesmos membros do Conselho dc Segurança, mais o Canadá, que teve sua sessão de instalação em junho de 1946. Face às peripécias da Guerra Fria, em especial as oposições entre o plano Baruch-Lilienthal dos EUA (criação de uma auto ridade independente da ONU para as medidas de desarmamento nuclear, e portanto não submetida às vicissitudes do veto) e o plano Gromyko da URSS (controle pelas autoridades nacionais do desarmamento nuclear e acionamento dos mecanismos já existentes na ONU, no caso de violação dos compromissos), e, em especial após a recusa da URSS de participar dos trabalhos de ambas as comissões, foram elas dissolvidas em 1952 e substituídas por uma única Comissão de Desarmamento das Nações Unidas, cujos trabalhos, a partir do ano seguinte, teriam um encaminhamento diferente; a lógica nuclear viria a introduzir novos elementos nas questões do desarmamento.

Por volta dos inícios da década dos anos 50, já havia prova de não ser verdadeira a idéia da raridade do urânio, matéria-prima das armas nucleares e dos combustiveis dos reatores comerciais de produção de energia para usos civis, fato que abrandava a posição do segredo militar dos EUA a tudo quanto se referisse a energia nuclear. Por outro lado, a URSS já tinha experimentado, com sucesso, os testes com suas armas nucleares, o que representaria, de seu lado, a perda do monopólio bélico-nuclear dos EUA. Concomitantemente, verificava-se a extrema importância da utilização da energia nuclear para finalidades civis (cujas conseqüências no comércio internacional de combustiveis nucleares e de reatores nucleares, tanto aos EUA quanto URSS e aos países da Europa Ocidental não poderiam deixar de passar despercebidas), e todos esses fatores e outros mais, conduziram, em 1953, o Presidente Eisenhower a propor, em discurso perante a Assembléia Geral da ONU, um programa de cooperação internacional na utilização da energia nuclear, denominado ÁTOMOS PARA A PAZ.

A partir de então, a questão do desarmamento nuclear segue seu caminho tormentoso, quer nas discussões da Comissão de Desarmamento da ONU, quer aos contatos bilaterais EUA-URSS, em foros especializados (Genebra e Helsinky), enquanto a idéia da utilização pacífica da energia nuclear se encaminha para a constituição, $\mathrm{em}$ 1955, por ocasião da Conferência Internacional sobre a Utilização Pacífica da Energia Atômica, reunida em Genebra, da AGÊNCIA 
INTERNACIONAL DE ENERGIA ATÔMICA (AIEA), que seria sediada em Viena (tratado assinado em 26 de outubro de 1956, em Genebra, e no Brasil promulgado pelo Decreto $n^{\circ} 42.155$, «D.O.U.» de 3 de setembro de 1957).

Outro fator a enfatizar, foi o de que na questão do desarmamento, segundo concebida nos termos da Carta de São Francisco, houve im. portante transformação de conceitos: de uma tentativa de desarmamento total de forças convencionais, idéia herdada do Entre-Guerras, tornada infactível pela emergência das armas nucleares e pelo espraiamento de sua tecnologia e pelo formidável avanço dos engenhos balísticos intercontinentais, evolui-se para a idéia de medidas parciais, sem dúvida limitadas, e portanto, possivelmente mais palatáveis aos Estados.

Em curso proferido na Academia de Direito Internacional de Haia, em 1971, o Prof. Eric Stein enuncia tais medidas parciais, que ele denomina "collateral measures» (Recueil des Cours, tomo 133, voi. II, 1971, «Impact of New Weapons Technology on International Law: Select Aspects», p. 250 e ss).

A primeira medida de controle parcial dos armamentos nucleares estabelecida no tempo foi a mencionada AIEA, em 1957. Seus objetivos podem ser brevemente resumidos como sendo de fundo positivo, tais: a disseminação de conhecimentos e incentivo à pesquisa sobre utilização pacífica da energia nuclear, de normas de utilização de radioisótopos nas atividades civis, de elaboração de normas de pro. teção ao trabalhador nas atividades nucleares pacíficas, em colaboração com a OIT e a OMS; bem como um completo sistema, e estes seus objetivos de fundo negativo, de controle do espraiamento de ma. teriais físseis ou férteis, advindos de cooperação bilateral entre Estados, em atividades com fins pacíficos, com a instituição de mecanismos de salvaguardas e inspeções por funcionários internacionais.

Outra medida de controle parcial dos efeitos da guerra nuclear, a título preventivo, foi o Memorando de Entendimento assinado em 20 de junho de 1963 entre EUA e URSS e que levaria à instalação entre as sedes dos respectivos Governos do denominado «Telefone Vermelho», linha de telecomunicações direta, num esforço de diminuiı a «sindrome do ataque de surpresa» (ou melhor dito, a sindrome do pânico do primeiro ataque), que ainda estava presente na memória dos homens, causado pela «crise dos foguetes em Cuba» e que daria ensejo ao exame entre a URSS e os EUA das tentativas de entrega de armas nucleares aos aliados. O Prof. Stein aponta, com razão, igualmente, na crise dos foguetes, a raiz dos posteriores entendimentos entre a URSS e os EUA das conversações sobre a limitação dos armamentos estratégicos (Acordos SALT), acontecidos em Helsinky e Viena.

Se as medidas parciais de desarmamento descritas anteriormente podem ser consideradas como dirigidas a controles globais relativos 
à prevenção das guerras nucleares, outras se destinam exclusivamente a proibição de operacionalizar armas nucleares em espaços habitados (Tratado de Moscou de 1963, o TNP de 1968 e o Tratado de Tlatelolco de 1967) e em espaços recentemente acessíveis ao homem (o Tratado da Antártica de 1959, o Tratado sobre o Espaço Sideral de 1967 e o Tratado dos Fundos Marítimos de 1970). Cada tratado dos mencio nados, tiveram motivações diferentes, com intuitos distintos uns dos outros e foram votados em foros diversos; o que lhes dá uniàade é de serem normas importantes, escritas, que regulam aspectos primordiais do «Jus ad Bellum», que na verdade, pelas considerações anteriores, melhor seria denominado de «Jus ad Athomicum Bellum», uma vez que a guerra convencional tem sua importância grandemente decrescida, com o advento do armamento nuclear, assim como estar a paz global dos dias que correm, na dependência da não utilização das armas de destruição maciça.

O Tratado de Moscou, melhor dito, «Tratado de Proscrição das Experiências com Armas Nucleares na Atmosfera, no Espaço Cósmico e sob a Água», assinado naquela cidade em 5 de agosto de 1963 (promulgado no Brasil pelo Decreto $n^{\circ} 58.256$ de 26 de abril de 1966), proíbe, às partes signatárias, de «efetuar qualquer explosão experimental de armas nucleares ou qualquer explosão nuclear (o que queĩ dizer, inclusive, das denominadas explosões nucleares com fins pacíficos em obras de engenharia civil) em qualquer lugar sob sua jurisdição ou controle: a) na atmosfera; alêm dos seus limites, inclusive no espaço cósmico; ou sob a água, inclusive águas territoriais e alic mar; ou b) em qualquer outro ambiente, desde que tal explosão provoque a queda de resíduos radioativos fora dos limites territoriais do Estado sob cuja jurisdição ou controle foi efetuada a explosão... (Texto apud Vicente Marotta Rangel, Direito e Relacões Internacionais, São Paulo, RT, 1ª ed., 1971, pg. 131 e ss.). Há igualmente proibições para os Estados de provocar, encorajar ou participar de qualquer maneira na realização de explosões nucleares, nas condições descritas, po1 terceiros Estados.

O TNP, em sua denominação oficial, «Tratado de Não-Proliferação das Armas Nucleares», foi apresentado pelos EUA e URSS à Comissão de Desarmamento da ONU em 11 de março de 1968, representando, assim, medida de retomada das discussões sobre desarma mento já a um nível internacional (e não meramente bilaterai), numa insofismável prova de que as questōes relativas a semelhante proble ma interessam a todos os Estados e não somente àqueles que se abalançam em garantes bilaterais da segurança internacional. Seu texto oficioso em português se encontra in Vicente Marotta Rangel, op. cit., p. 135 a 140. Interessa um exame de seus termos gerais, assim como das circunstâncias de sua vigência no espaço e no tempo, tarefa de cuja divulgação se tem incumbido a AIEA, através do mais amplo noticiário no seu Bulletin.

O TNP divide os signatários em Estado nuclear (que por vezes denomina de Potência Nuclear), «aquele que tenha fabricado e pro- 
vado uma arma nuclear ou qualquer outro engenho nuclear explosivo antes de $1^{\circ}$ de janeiro de 1967» (art. IX, $\S 3^{\circ}$ in fine) e Estado não nuclear, para impor aos primeiros a obrigação de «não transferir a terceiros, quem quer que sejam, armas nucleares ou outros engenhos explosivos nucleares, nem o controle direto ou indireto sobre tais armas e engenhos nucleares; também concorda em não ajudar, incen tivar ou induzir, de qualquer modo, qualquer Estado não nuclear a fabricar ou adquirir armas nucleares ou outros engenhos nucleares explosivos, ou o controle sobre tais armas ou engenhos explosivos» (art. 10). O principal defeito do TNP é, assim, o fato de impedir a proliferação horizontal dos armamentos nucleares de maneira discriminatória, permitindo a proliferação vertical dos barões do átomo. Foi por tais motivos, que Mario Pessoa no seu Leis de Guerra e Armas Nucleares, São Paulo, Ed. Revista dos Tribunais, 1969, com justa razão denominou o TNP de um novo Tordesilhas nuclear, onde os Estados Nucleares dividiram o mundo entre os «have» e os «have not». Por outro lado, levando-se em conta a possibilidade de no futuro realizarem-se explosões nucleares com finalidades pacíficas, no que sc convencionou chamar de engenharia continental, aquela discriminaçăo se torna ainda mais odiosa. São tais motivos que impediram, na América Latina, em especial Brasil e Argentina de absterem-se de assinar o TNP.

Disposição importante no TNP é destinada a reforçar o papei da AIEA na aplicação das salvaguardas. Trata-se do art. III, $\S 2$, verbis: «cada Estado participante deste Tratado concorda em não fornecer: a) a fonte de produção ou material físsil especial ou b) equipamento ou material especialmente destinado ou preparado para o processamento, uso ou produção de material físsil espedial, a qualquer Estado não-nuclear para fins pacíficos, a menos que a fonte de produção ou o material físsil especial sejam submetidos às medidas de segurança convencionadas neste artigo» (ou seja, as salvaguardas da AIEA). Quanto às explosões nucleares para fins pacíficos, o art. $\mathrm{V}$ do TNP as admite, nos seguintes termos: «cada participante deste Tratado concorda em cooperar para garantir que os benefícios em potencial de quaisquer aplicações pacíficas das explosões nucleares sejam postas à disposição, através de procedimentos internacionais adequados, dos Estados não-nucleares, Partes do presente Tratado, em base não discriminatória, bem como a responsabilidade dessas Partes pelos engenhos explosivos utilizados, seja a menos possível, excluindo-se qualquer responsabilidade pela pesquisa e desenvolvimento ...

O Tratado de Tlatelolco, assim chamado por ter sido assinado na Chancelaria mexicana, localizada no bairro com aquele nome asteca, denomina-se, oficialmente, Tratado para a Proscrição de Armas Nucleares na América Latina, assinado na cidade do México, a 14 de fevereiro de 1967, por esforços do Presidente mexicano, o que lhe valeria o Prêmio Nobel da Paz em 1982, o insigne estadista Alfonso Garcia Robles. Tem o principal mérito de ser o primeiro tratado que declara uma parte habitada do globo terrestre como livre de 
armamentos nucleares. São suas partes signatárias, tão somente os Estados latino-americanos e, para que os Estados extra-latino-americanos que detêm soberania sobre porções na América Latina (Paísè̀ Baixos, França, Grã-Bretanha e EUA), assim como Estados que tenham explodido armas nucleares (EUA, URSS, França, Grã-Bretanha e R.P. da China), se vinculem ao sistema normativo do Tratado, foram imaginados dois Protocolos Adicionais, que na atualidade se acham em vigor. A India se tem recusado a assinar o Protocolo Adicional II por afirmar que em maio de 1974 realizou uma explosão de um dispositivo nuclear e não de uma bomba ou qualquer outra arma nuclear.

$\mathrm{O}$ art. $1^{\circ}$ do Tratado de Tlatelolco define as obrigações que insti. tui, nos seguintes termos: «As Partes Contratantes comprometem-se a utilizar, exclusivamente com fins pacíficos, o material e as instalações nucleares submetidos à sua jurisdição, e a proibir e a impedir nos respectivos territórios: a) o ensaio, uso, fabricação, produção ou aquisição, por qualquer meio, de toda arma nuclear, por si mesmas, direta ou indiretamente, por mandato de terceiros ou em qualquer outra forma e, b) a recepção, armazenamento, instalação, colocação ou qualquer forma de posse de qualquer arma nuclear, direta ou indiretamente, por si mesmas, por mandato de terceiros ou de qualquer cutro modo. $\S 2^{\circ}$ - As Partes Contratantes comprometem-se, iguaimente, a abster-se de realizar, fomentar ou autorizar, direta ou indi retamente, o ensaio, o uso, a fabricação, a produção, a posse ou o dominio de qualquer arma nuclear ou de participar nisso de qualquer maneira». Ao lado de tantas e minuciosas proibições, contudo, uma não foi possível antever: a do trânsito de armas nucleares pela zoń́ de aplicação do Tratado e a França, ao subscrever o Protocolo Ad̄icional I e II, declarou que não poderia abdicar de um direito à sua soberania de colocar armas nucleares nos territórios a ela submetidos e situados na América Latina.

No Tratado de Tratelolco, pela primeira vez, aparece a definição jurídica de arma nuclear, num texto normativo internacional. Estatui seu art. 5", verbis: «Para os efeitos do presente Tratado, entende-se por arma nuclear qualquer artefato que seja suscetivel de liberar energia nuclear de forma não controlada e que tenha um conjunto de características próprias para seu emprego com fins bélicos. $\$ 2^{\circ}$ $O$ instrumento que se possa utilizar para o transporte ou a propulsão do artefato não fica compreendido nesta definição, se é separável do artefato e não parte indivisível do mesmo». Claro está a imperfeição técnica de semelhante definição de arma nuclear, pois inexistem fatores tecnológicos que possam diferenciar uma arma nuclear de um dispositivo explosivo nuclear com finalidades pacíficas; contudo, não deixa de ser louvável o esforço do legislador internacional ao buscar definir o que considera arma nuclear, o fator de proibição central do Tratado de Tlatelolco.

Cria-se, no sentido de aplicar os termos do Tratado, uma Agência para a Proscrição de Armas Nucleares na América Latina, no jargão 
jornalístico, a OPANAL ( $\mathrm{O}$ », de organismo, sua denominação no texto em espanhol), organismo internacional regional com sede na cidadt do México. Além de contar com inspetores próprios e um sistema de salvaguardas, a OPANAL tem vinculação direta com a AIEA, a Assembléia Geral da ONU e seu Conselho de Segurança, apresentando-se, assim, como mais um instrumento de vigilância na não-proliferação nuclear na América Latina.

O Tratado de Tlatelolco já se encontra vigente no mundo norma tivo. Contudo, o Brasil, ao assiná-lo, fez uso de uma faculdade que o texto lhe permitia: de estar o tratado vigente entre todos os Estados da América Latina e sabemos que Cuba se tem recusado a assinar o mesmo (que ela considera como altamente discriminatório e que representa uma posição muito afirmativa da política do «imperialismo norte-americano»).

No que respeita a medidas colaterais de desarmamento nuclear devemos considerar, ainda, três tratados que pretendem impedir a colocação de armas nucleares em espaços recentemente acessíveis ao homem.

O mais antigo, o Tratado da Antártica de 1959 estatui no seli art. V, verbis: «Ficam proibidas as explosões nucleares na Antártica, bem como o lançamento ali de lixo ou resíduos radioativos. $\S 2^{\circ}$ - No caso de conclusão de acordos internacionais sobre a utilização da energia nuclear inclusive as explosões nucleares e o lançamento de resíduos radioativos, de que participem todas as Partes Contratantes, cujos representantes estejam habilitados a participar das reuniōes pre vistas no artigo X, aplicar-se-ão à Antártica as regras estabelecidas em tais acordos».

O Tratado sobre o Espaço Sideral, cuja denominação oficial é Tratado sobre Princípios Reguladores das Atividades dos Estados na Exploração e Uso do Espaço Cósmico, Inclusive a Lua e Demais Corpos Celestes, foi adotado pela Assembléia-Geral das Nações Unidas, em 19 de dezembro de 1966 e aberto à assinatura em Londres, Moscou e Washington, a 17 de janeiro de 1967. No Brasil, encontra-se pro mulgado pelo Decreto $n^{\circ} 64.362$, de 17 de abril de 1969 («D.O.U. de 22 de abril do mesmo ano). Dispõe o seu Art. IV, verbis: «Os Estados-partes do Tratado se comprometem a não colocar em órbita objeio portador de armas nucleares ou de qualquer outro tipo de armas de destruição em massa, a não instalar tais armas sobre os corpos celestes e a não colocar tais armas, de nenhuma maneira, no espaço cósmico. $\S 2^{\circ}$ - Todos os Estados-partes do Tratado utilizarão a Lua e os demais corpos celestes exclusivamente para fins pacíficos. Estarão proibidos nos corpos celestes o estabelecimento de base, instalações e fortificações militares, os ensaios de armas de qualquer tipo e à execução de manobras militares. Não se proíbe a utilização de pessoal militar para fins de pesquisas científicas ou para qualquer outro fim pacífico. Não se proíbe, do mesmo modo, a utilização de qualquer 
equipamento ou instalação necessária à exploração pacífica da Lua e demais corpos celestes».

Enfim, o mais recente Tratado para a Proibição de Colocação de Armas Nucleares e Outras Armas de Destruição Maciça nos Leitos Marítimos e nos Fundos Oceânicos e no Seu Subsolo, foi aberto à assinatura na Assembléia Geral da ONU, desde outono de 1970. Importa transcrever os artigos iniciais, cujo texto se encontra apud Alva Myrdal, «No Arms on the Ocean Floor» in Pacem in Maribus, edit. por Elisabeth Borgese, Dodd, Mead \& Co., Nova York, 1972, Art. I, 1. Os Estados Partes no presente Tratado se comprometem a não instalar nem colocar nos fundos marítimos e oceânicos e no seu subsolo, além do limite exterior da zona dos fundos marítimos definida no art. II, armas nucleares, nem qualquer outro tipo de armas de destruição maciça, assim como também estruturas, instalação de lançamento ou outras instalações destinadas expressamente a armazenar, testar ou utilizar tais armas. $\S 2^{\circ}$ - As obrigações contraídas segundo o $\S 1^{\circ}$ deste artigo serão aplicáveis, também à zona dos fundos marítimos mencionada no mesmo parágrafo, com a ressalva de que, dentro dessa zona dos fundos maritimos, não se aplicarão ao Estado ribeirinho, nem aos fundos maritimos de suas águas territoriais. $\S 3^{\circ}-$ Os Estados Partes no presente Tratado se comprometem a não dar assistência e encorojamento e a não induzir a qualquer Estado a realizar as atividades mencionadas no $\S 1^{\circ}$ deste Artigo, e a não participar de qualquer modo, em tais atos». Art. $\Pi$ : «Para os efeitos do presente Tratado, o limite exterior da zona dos fundos maritimos a que se refere o art. I, coincidirá com o limite exterior de doze milhas da zona mencionada na parte $I I$ da Convenção sobre Mar Territorial e Zona Contígua, assinada em Genebra em 29 de abril de 1958, e se medirá de acordo com o disposto na seção III da parte I da citada Convenção e de acordo com o direito internacional».

Podem-se antever as dificuldades na aplicação dos princípios do referido Tratado sobre os Fundos Marítimos, em especial, quando se defronta com a oposição de Estados que adotam o limite das 200 milhas maritimas para delimitar seu mar territorial. De qualquer forma, o mencionado Tratado tem o mérito de tentar fixar a responsabilidade de não-colocação de armas nucleares naqueles espaços marítimos e no seu subsolo.

\section{IV - CONCLUSõES}

Após a constatação da total impossibilidade de aplicar-se o Direito da Guerra na eventualidade de um conflito nuclear, dissemos que passa a ganhar transcendental importância o Direito de Prevenção de Guerra, que batizamos de JUS AD ATHOMICUM BELLUM, na esteira dos conceitos do Prof. Louis Delbez.

$\mathrm{Na}$ verdade, as tentativas de prevenir a eclosão de um conflito nuclear generalizado passam a ser a preocupação central doo Direito Internacional da atualidade. 
O exame dos textos normativos de prevenção da guerra nucleai revelam falhas, imperfeições, vários pontos de possivel escapismo por parte dos Estados. Contudo aí estão vigentes e se os Estados quiserem aplicá-los e evitar a guerra nuclear, é só fazê-lo, após a demonstração de vontade política para tal.

Sepultado o Direito da Guerra, só resta ao homem do Século XX lutar com todas as suas forças para evitar a guerra nuclear, que, se eclodida, representará a última guerra que o homem, na sua feição que conhecemos e que nos vemos no espelho, travará contra seus semelhantes. A Quarta Guerra, no dizer de Einstein, será levada avante com pedras e machados de madeira, e acrescente-se, por simulacros dos homens que atualmente vivem no planeta Terra.

\section{BIBLIOGRAFIA DE APOIO}

Delbez, Louis Les Principes Généraux du Droit International Public Droit de la Paix, Droit Préventif de la Guerre, Droit de la Guerre, $3^{\text {a }}$ ed., Paris, Lib. Gén. de Droit et de Jurisprudence, 1964.

Garcia Robles, Alfonso «Mesures de Désarmement dans les Zones Particulières: le Traité visant l'Interdiction des Armes Nucléaires en Amérique Latine» in 133 Recueil des Cours, 1971, Haia, Sejthof.

Pessoa, Mario Leis de Guerra e Armas Nucleares, São Paulo, Ed. Revista dos Tribunais, 1969.

Rousseau, Charles Droit International Public, Paris, Dalloz, 6* ed., 1971.

Soares, Guido Fernando Silva Contribuição do Estudo da Política Nuclear Brasileira, tese de doutoramento em Ciência Política (Política Internacional), apresentada em 30 de março de 1974, à Pontifícia Universidade Católica de São Paulo (não publicada).

As Salvaguardas nos Acordos Nucleares Brasil-EUA e Brasil-R.F. da Alemanha, São Paulo, Bushatsky, Coleção Juridica JB no 17, 1976.

Stein, Eric «Impact of New Weapons Technology on International Law. Select Aspects》 in Recueil des Cours, tomo 133. 1971, Haia, Sejthof.

Coletânea de Tratados $\mathrm{e}$ atos internacionais:

Rangel, Vicente Marotta Direito e Relacões Internacionais, Textos Organizados por, São Paulo, Ed. Revista dos Tribunais, 29 edição revista e aumentada, 1981. 